\title{
Chapter 4 \\ Ferrets as a Model for Morbillivirus \\ Pathogenesis, Complications, and Vaccines
}

\author{
S. Pillet, N. Svitek, and V. von Messling $(\bowtie)$
}

\begin{abstract}
Contents

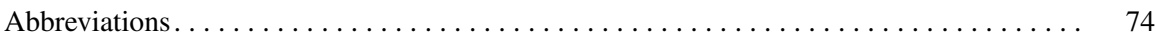

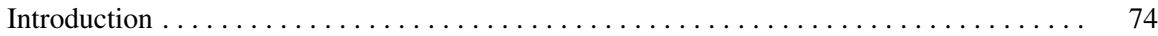

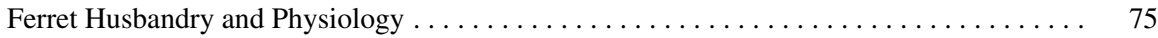

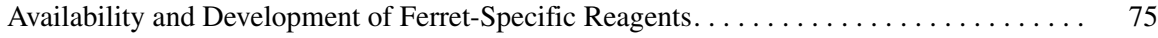

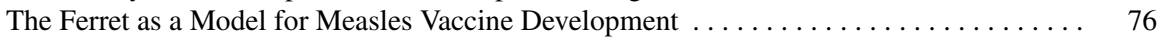

The Role of Maternal Antibodies for Measles Vaccination Strategies . . . . . . . . . 76

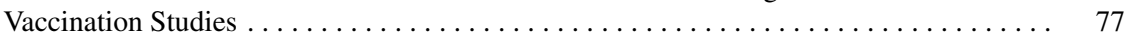

The Ferret as Model for Measles-Induced Immunosuppression . . . . . . . . . . . . . . . . 79

The Ferret as Model for Measles-Associated Neurological Complications . . . . . . . . . . 80

Overview of Morbillivirus-Associated Central Nervous System Complications . . . . . . 80

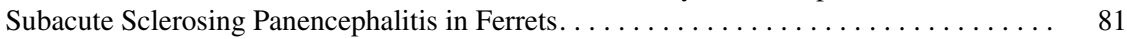

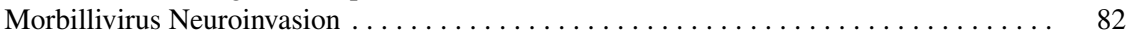

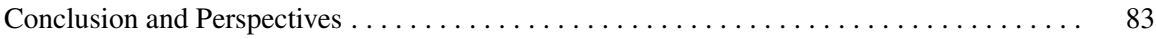

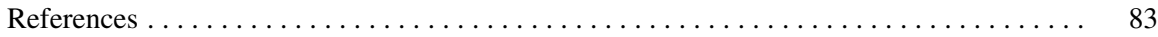

\begin{abstract}
The ferret is a standard laboratory animal that can be accommodated in most animal facilities. While not susceptible to measles, ferrets are a natural host of canine distemper virus (CDV), the closely related carnivore morbillivirus. CDV infection in ferrets reproduces all clinical signs associated with measles in humans, including the typical rash, fever, general immunosuppression, gastrointestinal and respiratory involvement, and neurological complications. Due to this similarity, experimental CDV infection of ferrets is frequently used to assess the efficacy of novel vaccines, and to characterize pathogenesis mechanisms. In addition, direct intracranial inoculation of measles isolates from subacute sclerosing panencephalitis (SSPE) patients results in an SSPE-like disease in animals that survive the acute phase. Since the advent of reverse genetics systems that allow the targeted manipulation of viral genomes, the model has been used to evaluate the contribution of the accessory proteins $\mathrm{C}$ and $\mathrm{V}$, and signalling lymphocyte activation molecule (SLAM)binding to immunosuppression and overall pathogenesis. Similarly produced green
\end{abstract}

\footnotetext{
V. von Messling

INRS-Institut Armand-Frappier, University of Quebec, 531, boul. des Prairies, Laval, QC,

H7V 1B7, Canada, e-mail: veronika.vonmessling@iaf.inrs.ca
} 
fluorescent protein-expressing derivatives that maintain parental virulence have been instrumental in the direct visualization of systemic dissemination and neuroinvasion. As more immunological tools become available for this model, its contribution to our understanding of morbillivirus-host interactions is expected to increase.

\section{Abbreviations}

$\begin{array}{ll}\text { ADEM } & \text { Acute disseminated encephalomyelitis } \\ \text { CAV2 } & \text { Canine adenovirus type 2 } \\ \text { CDV } & \text { Canine distemper virus } \\ \text { CNS } & \text { Central nervous system } \\ \text { eGFP } & \text { Enhanced green fluorescent protein } \\ \text { F } & \text { Fusion } \\ \text { H } & \text { Hemagglutinin } \\ \text { IFN } & \text { Interferon } \\ \text { Ig } & \text { Immunoglobulin } \\ \text { IL } & \text { Interleukin } \\ \text { MV } & \text { Measles virus } \\ \text { MHC } & \text { Major histocompatibility complex } \\ \text { MIBE } & \text { Inclusion body encephalitis } \\ \text { N } & \text { Nucleocapsid } \\ \text { P } & \text { Phosphoprotein } \\ \text { SLAM } & \text { Signalling lymphocyte activation molecule } \\ \text { SSPE } & \text { Subacute sclerosing panencephalitis }\end{array}$

\section{Introduction}

Domestic ferrets (Mustela putorius furo) belong to the family Mustelidae, which also includes weasels, minks, martens, sables, skunks, otters, and badgers, in the order Carnivora (McKenna and Bell 1997). Due to their relatively small size and natural susceptibility to a broad range of respiratory viruses, ferrets are an attractive animal model for pathogenesis research and the development of new vaccines and treatment approaches (Hsu et al. 1994; Maher and DeStefano 2004; Osterhaus et al. 2004). While they do not develop signs of disease upon intranasal infection with measles virus (MV), intracranial inoculation of certain subacute sclerosing panencephalitis (SSPE) isolates results in a histopathologically similar subacute encephalitis (Thormar et al. 1985). In addition, ferrets are a natural host for canine distemper virus (CDV), a close relative of MV that infects a broad range of carnivores. They develop all signs of disease seen in MV-infected humans, including the characteristic rash, but usually succumb to the infection (von Messling et al. 2003). This clinical similarity combined with the high sensitivity make the study of CDV in ferrets an ideal model to characterize MV pathogenesis mechanisms. 


\section{Ferret Husbandry and Physiology}

Ferrets have long tubular bodies with short legs, and they are very flexible. While most rabbit and cat cages correspond to regulatory requirements for the housing of ferrets in experimental settings, they require adaptation to prevent the animals' escape through feeders or other small openings. Ferrets are generally friendly and display a broad range of behaviors. Whenever possible, they should be housed in groups and appropriate toys should be provided to avoid boredom. They can be fed ad libitum with commercially available cat food, and food should not be withheld for more than $6 \mathrm{~h}$ because of their rapid metabolism (Fox 1998; Moody et al. 1985).

Ferrets reach sexual maturity around 6-8 months of age, with the weight of adult males reaching up to $2 \mathrm{~kg}$, while females will weigh between 0.5 and $1 \mathrm{~kg}$. Measurement of the rectal temperature and subcutaneous and intramuscular injections require only scruffing of the loose skin on the back of the neck, while intravenous injections and venipunctures are greatly facilitated by general anesthesia. This can be either achieved by intramuscular injection of a combination of ketamine and either midazolam, xylazine, or acepromazine, or by inhalation of isoflurane. Ferrets have a total blood volume of approximately $60 \mathrm{ml} / \mathrm{kg}$, and $10 \%$ can be safely withdrawn once every 2 weeks. The most commonly used site for venipuncture is the jugular vein, but the anterior vena cava can also be used. For smaller volumes, the lateral saphenous or the cephalic vein and the tail artery are an alternative option. A detailed description of the techniques involved can be found in Quesenberry (1996).

\section{Availability and Development of Ferret-Specific Reagents}

The limited availability of ferret-specific immunological reagents has been a major drawback of this animal model. Aside from secondary antisera to ferret IgG, IgM, IgA, an increasing number of cross-reacting antibodies against various epitopes have become commercially available (Table 4.1). In addition, the susceptibility of ferrets to influenza and SARS (Maher and DeStefano 2004; Osterhaus et al. 2004) has led to an increased effort to develop ferret-specific reagents. Several ferret cytokine and chemokine sequences have been published in GenBank, and PCRbased assays have been developed to assess gene expression (Danesh et al. 2008; Senchak et al. 2007; Svitek and von Messling 2007). While ferret-specific proteinbased assays are still rare (Ochi et al. 2008), the potential applicability of commercial canine or feline tests can now be evaluated based on sequence homology comparisons. The recent addition of the ferret genome to the sequencing targets approved by the NIH National Human Genome Research Institute will further accelerate the development of this model. 
Table 4.1 Noncomprehensive list of cross-reactive antibodies commercially available for ferrets

\begin{tabular}{|c|c|c|}
\hline Antibody & Clone & Company \\
\hline Mouse monoclonal anti-CD79A & HM47 & $\begin{array}{l}\text { Santa Cruz } \\
\text { Biotechnology, CA }\end{array}$ \\
\hline Mouse monoclonal anti-CD79 $\alpha$ cy & HM57 & DakoCytomation, CA \\
\hline Mouse monoclonal anti-CD3 & $\mathrm{PC} 3 / 188 \mathrm{~A}$ & $\begin{array}{l}\text { Santa Cruz } \\
\quad \text { Biotechnology, CA }\end{array}$ \\
\hline Mouse monoclonal anti-CD3 & F7.2.38 & DakoCytomation, CA \\
\hline Mouse monoclonal anti-CD14 & CAM36A & VMRD, WA \\
\hline Mouse monoclonal anti-CD172a & DH59B & VMRD, WA \\
\hline Mouse monoclonal anti-CD18 & BAQ30A & VMRD, WA \\
\hline Mouse monoclonal anti-CD21-like & F46A & VMRD, WA \\
\hline Mouse monoclonal anti-CD41/46 & CL2A & VMRD, WA \\
\hline Mouse monoclonal anti-CD44 & BAG40A & VMRD, WA \\
\hline Mouse monoclonal anti-MHC I & $\mathrm{H} 58 \mathrm{~A}$ & VMRD, WA \\
\hline Mouse monoclonal anti-MHC II & CAT82A & VMRD, WA \\
\hline $\begin{array}{l}\text { Mouse monoclonal anti-MHC II } \\
\text { (HLA-DP) }\end{array}$ & $\mathrm{H} 425 \mathrm{~A}$ & VMRD, WA \\
\hline $\begin{array}{l}\text { Mouse monoclonal anti-MHC II } \\
\text { (HLA-DQ) }\end{array}$ & TH81A5 & VMRD, WA \\
\hline $\begin{array}{l}\text { Mouse monoclonal anti-MHC II } \\
(\text { HLA-DR } \alpha)\end{array}$ & TH14B & VMRD, WA \\
\hline $\begin{array}{l}\text { Mouse monoclonal anti-MHC II } \\
\text { (HLA-DR) }\end{array}$ & $\mathrm{H} 34 \mathrm{~A}$ & VMRD, WA \\
\hline $\begin{array}{l}\text { Mouse monoclonal anti-keratin } \\
\text { Pan Ab-3 }\end{array}$ & Lu-5 & NeoMarkers, CA \\
\hline $\begin{array}{l}\text { Rabbit polyclonal anti-glial } \\
\text { fibrillary acidic protein }\end{array}$ & - & DakoCytomation, CA \\
\hline $\begin{array}{l}\text { Rabbit polyclonal anti-Von } \\
\text { Willebrand Factor }\end{array}$ & - & DakoCytomation, CA \\
\hline $\begin{array}{l}\text { Goat polyclonal anti-ferret } \\
\text { IgG } \mathrm{H} \text { and } 1 \text { chains }\end{array}$ & - & Bethyl Laboratories, TX \\
\hline Goat polyclonal anti-ferret $\operatorname{IgA} \alpha$ & - & $\begin{array}{l}\text { Rockland } \\
\text { Immunochemicals, PA }\end{array}$ \\
\hline Goat polyclonal anti-ferret $\operatorname{IgM} \mu$ & - & $\begin{array}{l}\text { Rockland } \\
\text { Immunochemicals, PA }\end{array}$ \\
\hline
\end{tabular}

\section{The Ferret as a Model for Measles Vaccine Development}

\section{The Role of Maternal Antibodies for Measles Vaccination Strategies}

In addition to the immaturity of the infant's immune system, the poor response to MV vaccination observed in infants under 1 year of age has also been linked to the presence of maternal antibodies (Gans et al. 1998; Schluederberg et al. 1973; Wilkins and Wehrle 1979). Thus, maternal antibodies are an important consideration for MV vaccination development and for the ongoing eradication 
campaign. Ferrets and dogs have been extensively used to characterize the interactions of live-attenuated morbillivirus vaccines with maternal antibodies. Since both species are highly susceptible to CDV, annual vaccination with a live-attenuated vaccine similar to that used in humans is recommended. Consequently, ferret kits and puppies are born with maternal antibodies that diminish as the animal ages. In ferret kits born to mothers vaccinated with a modified-live CDV vaccine of chicken tissue culture origin, virus-specific maternal antibodies have a half-life of approximately 9 days and reach levels below the detection limit after 12 weeks (Appel and Harris 1988), levels comparable to maternal canine parvovirus antibodies transferred to puppies (Pollock and Carmichael 1982). Despite this shorter half-life of maternal antibodies, ferrets and dogs thus recapitulate the overall aspects of maternally acquired anti-MV antibodies in human infants (Gans et al. 1998).

In a study using a recombinant canarypox virus expressing the CDV fusion (F) and hemagglutinin $(\mathrm{H})$ proteins, only $14 \%$ survival was seen in ferret kits with preexisting maternal immunity after mucosal or parenteral immunization with the recombinant candidate vaccines, despite high levels of neutralizing antibodies at the time of challenge. However, the percentage of survival increased to $33 \%$ when animals were inoculated by the combined parenteral/mucosal route (Welter et al. 2000), suggesting that multiple routes of inoculation may be advantageous. In puppies, maternal antibody interference can be efficiently overcome by the use of the same canarypox-based vaccine, a similarly constructed adenoviral vector, or DNA vaccination with a mixture of plasmids coding for the CDV nucleocapsid (N), phosphoprotein (P), and H genes (Fischer et al. 2002, 2003; Griot et al. 2004; Pardo et al. 2007). In all cases, the vaccination elicited an increase in neutralizing antibodies, and all animals were protected from subsequent challenge. This difference in vaccine efficacy observed between dogs and ferrets is likely due to differences in experimental setup and readout, but may also reflect the higher sensitivity of the latter to CDV infection. Taken together, these studies provide valuable insights for the development of MV vaccination strategies that retain the effectiveness in the presence of maternal antibodies.

\section{Vaccination Studies}

\section{Modified-Live and Inactivated Vaccines}

Ferrets and dogs have also been used to assess the efficacy of new CDV candidate vaccines and novel vaccination strategies. Early studies demonstrated the efficacy of the live-attenuated CDV vaccines upon subcutaneous and intramuscular inoculation, but also raised concerns because of the residual immunosuppressive properties and the occasional anaphylactic reactions observed (Cabasso et al. 1953; Gorham et al. 1954; Greenacre 2003; Hoover et al. 1989; Morris et al. 1954; Rockborn et al. 1965; Shen et al. 1984; Stephensen et al. 1997; Williams et al. 1996; Wimsatt et al. 2001). To circumvent this problem, the cross-protective 
properties of the live-attenuated MV vaccine were evaluated in puppies that had no maternal antibodies. While none of the adverse effects associated with the CDV vaccine were observed, the level of protection conferred was variable (Appel et al. 1984; Chalmers and Baxendale 1994; Strating 1975). A comparative study of a beta-propiolactone-inactivated virus and the live-attenuated CDV vaccine revealed that both vaccines conferred protective immunity, even though neutralizing antibody levels were lower in the group receiving the inactivated product. However, animals receiving the live-attenuated vaccine developed a transient lymphopenia after vaccination, demonstrating again that the live-attenuated vaccine virus had retained some immunosuppressive properties (Williams et al. 1996). This residual virulence of the commercially available live-attenuated vaccines is particularly pertinent for the development of vaccination strategies for CDV-susceptible wildlife species in zoos or in conservation programs. Many of these species may develop severe disease or even die from inoculation with these vaccines. The near extinction of black-footed ferrets caused by a vaccination campaign is the best known example (Carpenter et al. 1976; Pearson 1977), but there are similar reports for several other species, including domestic ferrets (Bush et al. 1976; Carpenter et al. 1976; Ek-Kommonen et al. 2003; Gill et al. 1988; Greenacre 2003). It was initially recommended to use either an inactivated vaccine or the live-attenuated MV vaccine for highly sensitive or endangered species, possibly followed by inoculation with the live-attenuated CDV vaccine after verification of antibody titers (Loeffler et al. 2007; Qin et al. 2007; Wimsatt et al. 2003). However, since its approval in 1997 (Pardo et al. 1997), the recombinant canarypox vaccine expressing the CDV envelope glycoproteins has replaced these approaches. In addition to providing insight into the risks and limitations of liveattenuated vaccines, these studies constitute a framework for the development of vaccination strategies for immunosuppressed individuals.

\section{Novel Vaccine Candidates}

The main disadvantages of the currently commercially available live-attenuated morbillivirus vaccines lie in their temperature sensitivity and the need for intramuscular injection. Among the novel vaccine candidates brought forward to address these issues, recombinant poxviruses expressing the CDV envelope glycoproteins have been evaluated in ferrets (Stephensen et al. 1997). While the traditionally vaccinated group still experienced weight loss and developed erythematous rash and leukopenia, animals receiving the recombinant vaccine mounted a strong humoral immune response and were completely protected from clinical disease. This study provided the first proof-of-principle that recombinant poxviruses expressing morbillivirus $\mathrm{F}$ and $\mathrm{H}$ proteins elicit protective immunity. The same group subsequently demonstrated that these poxviral candidate vaccines were similarly efficacious upon intranasal inoculation while intraduodenal infection conferred only partial protection (Welter et al. 1999). In ferrets less than 12 weeks of age, vaccine efficacy was dependent on the absence of maternal antibodies (Welter et al. 2000). A similar 
vaccination strategy using two replication-competent canine adenovirus type 2 (CAV2) that expressed the CDV $\mathrm{F}$ and $\mathrm{H}$ proteins, respectively, was equally efficient in protecting CAV2 seronegative dogs from lethal challenge after intranasal inoculation (Fischer et al. 2002). In the presence of anti-CAV2 antibodies, this vaccine was only effective when inoculated via the subcutaneous route.

DNA-based vaccines have not yet been evaluated in ferrets; however, studies conducted in dogs and minks (Dahl et al. 2004) have provided the proof-of-concept for this type of vaccination. Dogs immunized with a combination of plasmids expressing the $\mathrm{CDV} \mathrm{N}, \mathrm{F}, \mathrm{H}$ proteins mounted a neutralizing immune response and were protected from challenge (Cherpillod et al. 2000). However, antibody titers markedly increased only after the third DNA immunization and reached high neutralizing values only after challenge. The formulation of plasmids encoding the $\mathrm{CDV} \mathrm{F}$ and $\mathrm{H}$ proteins with the cationic lipid DMRIE-DOPE resulted in significant seroconversion and protection from lethal intracranial challenge after the second immunization (Fischer et al. 2003). These studies demonstrate that several alternatives to the currently used live-attenuated vaccines are available and suggest that similar approaches may be applicable to MV.

\section{The Ferret as Model for Measles-Induced Immunosuppression}

Since the host range of MV is limited to humans and certain non-human primates, animal models using other morbilliviruses have been developed to characterize the mechanisms underlying the long-lasting immunosuppression associated with MV infection. The clinical and immunological similarities of the diseases caused by MV and CDV in their respective hosts, the fact that ferrets and dogs are common laboratory animals, and the lack of regulatory limitations restricting the work with ungulate morbilliviruses have resulted in preferential use of CDV-based models (Kauffman et al. 1982; Krakowka 1982; Krakowka et al. 1987; McCullough et al. 1974; von Messling et al. 2003, 2004). Ferrets or dogs infected with wild-type CDV strains develop the characteristic clinical signs of morbillivirus disease, including the typical rash, fever, and gastrointestinal and respiratory involvement. In addition, severe leukopenia, inhibition of lymphocyte proliferation upon nonspecific stimulation, and reduction or loss of delayed-type hypersensitivity reactions are observed within 1 week after infection (Griffin 2007; Kauffman et al. 1982; Krakowka et al. 1975; von Messling et al. 2003). This immunosuppression is sustained throughout the acute phase of the disease and may persist in dogs for weeks after virus clearance (McCullough et al. 1974; Schobesberger et al. 2005).

The ability to generate genetically modified wild-type viruses by reverse genetics and the introduction of an additional transcriptional unit encoding the enhanced green fluorescent protein (eGFP) in the viral genome have proven an invaluable tool for the characterization of virus-host interactions on the macroscopic and microscopic level (von Messling et al. 2004). Time course studies showed that the infection is initially limited to lymphatic tissues, where $\mathrm{T}$ and B cells are the primary targets. Spread to epithelia occurs only after massive infection of the immune 
system and coincided with the onset of clinical signs, followed by gradual neuroinvasion (Rudd et al. 2006). The extent of the lymphotropism observed, where over $70 \%$ of T and B cells were eGFP-positive within the 1st week of a wild type infection, illustrated the direct impact of the infection on the immune system (von Messling et al. 2004). The importance of immune cell infection for viral pathogenesis was further demonstrated by the inability of a signalling lymphocyte activation molecule (SLAM)-blind virus to spread and cause disease (von Messling et al. 2006).

Since ferrets usually succumb to the infection with wild-type CDV strains, the model is well suited for the characterization of genetic factors of immune evasion. A comparative study involving viruses that lacked the accessory proteins $\mathrm{V}$ and $\mathrm{C}$ either individually or in combination demonstrated the essential role of $\mathrm{V}$, while indicating that $C$ had a more subtle function (von Messling et al. 2006). Confirming findings from in vitro and murine studies with the corresponding recombinant MVs, a V-mediated block in cytokine induction was observed (Devaux et al. 2007; Fontana et al. 2008; Ohno et al. 2004; Palosaari et al. 2003). The subsequent analysis of cytokine profiles from animals that survived the infection revealed a response similar to that seen in patients with naturally acquired MV infection (Atabani et al. 2001; Moss et al. 2002; Svitek and von Messling 2007; Tetteh et al. 2003; Zilliox et al. 2007). The response was characterized by a strong interleukin (IL)-10 response as early as 3 days after infection, and sustained induction of cytokines of the proinflamatory or the TH1 and TH2 pathways such as IL-6, IL-2, IL-12p40, IL-4 and interferon (IFN)-gamma (Svitek and von Messling 2007). Taken together, these studies demonstrate the value of CDV-based models for the characterization of morbillivirus immunosuppression and highlight the complementarities of different experimental systems.

\section{The Ferret as Model for Measles-Associated Neurological Complications}

\section{Overview of Morbillivirus-Associated Central Nervous System Complications}

MV can result in early or late central nervous system (CNS) involvement. Based on onset, virus presence in the brain, and mitigating host factors, three distinct forms are recognized: acute disseminated encephalomyelitis (ADEM), which is thought to be mainly immune-mediated and occurs within 2-4 weeks after infection; inclusion body encephalitis (MIBE), a rare complication prevalent in immunocompromised patients, which develops within weeks after recovery and is associated with high amounts of replicating virus in the CNS; and SSPE, which manifests months to years after the initial infection and is characterized by the development and subsequent persistence of a highly cell-associated non-productive form of the virus (Griffin 2007; Sips et al. 2007). 
CDV is associated with one of the highest incidences of CNS complications among morbilliviruses. Up to $30 \%$ of dogs exhibit signs of neurologic involvement during or after CDV infection, and most wild carnivores that succumb to CDV display some evidence of CNS involvement (Appel and Summers 1995; Confer et al. 1975; Summers et al. 1984; van Moll et al. 1995). Similarly to MV, CDVinduced CNS complications can be categorized into acute encephalopathy, inclusion body polioencephalitis, and subacute to chronic demyelinating encephalitis (Krakowka et al. 1985). The Snyder Hill strain, which was selected for increased neurovirulence by multiple passages in dogs via intracerebral inoculation, induces acute encephalitis with high mortality that mimics the MV encephalitis seen in patients with acquired immune deficiency syndrome (Gillespie and Rickard 1956; McQuaid et al. 1998; Summers et al. 1984). In contrast, typical wild-type strains mainly induce demyelinating SSPE-like lesions in dogs. These lesions are first observed around 3 weeks postinfection and can progress even after the virus has been cleared from the periphery and the animal has recovered from the acute disease (Vandevelde et al. 1982; Vandevelde and Zurbriggen 2005). This chronic demyelinating encephalitis is characterized by perivascular cuffing, intracerebral infiltration of immune cells, MHC II upregulation, and increased levels of antiCDV antibodies in the cerebrospinal fluid, all hallmarks of SSPE (Alldinger et al. 1996; Dorries and Ter Meulen 1984; Nagano et al. 1991; Schneider-Schaulies et al. 1999; Vandevelde et al. 1986).

\section{Subacute Sclerosing Panencephalitis in Ferrets}

Forty years ago, Katz et al. (1968) inoculated ferrets intracerebrally with brain cell cultures from SSPE patients, producing acute encephalitis in these animals. In contrast to typical cell-associated nonproductive SSPE strains, wild-type MV strains and the efficiently replicating SSPE isolates did not cause detectable encephalitis in young ferrets. Subsequent studies showed that the course of disease depends on the respective cell-associated SSPE strain and the type of cell culture used for virus propagation (Thormar et al. 1985). However, despite severe clinical signs and large amounts of virus in the brain, only minor lesions and no humoral immune response or inflammatory changes were observed in the CNS, in contrast to human SSPE tissues (Brown et al. 1985).

In an attempt to reproduce SSPE more accurately, a nonproductive SSPE strain was inoculated into ferrets previously immunized with the live-attenuated MV vaccine. Among the 50\% of survivors, some developed subacute encephalitis weeks or months after inoculation (Mehta and Thormar 1979). The neurological signs observed in these ferrets had certain similarities to those seen in SSPE patients, leading to coma and death. Cell-associated nonproductive MV was always present in the brain and sometimes in the spinal cord, and widespread inflammatory lesions were observed in both the white and gray matter. Ferrets developing subacute encephalitis furthermore exhibited increased $\mathrm{IgG}$ concentrations in the cerebrospinal fluid, another hallmark of SSPE (Mehta and Thormar 1979; Thormar 
et al. 1983). The lack of antibodies against the viral matrix protein despite high titers against other structural proteins was also observed (Thormar et al. 1985). In a follow-up study, cell-associated nonproductive SSPE viruses were inoculated intracardially to elucidate the route of CNS invasion. Although infectious virus was not detectable in the blood of ferrets tested daily following inoculation, clinical signs and inflammatory lesions as well as the presence of viral antigens in the brain demonstrate the ability of the virus to spread to the CNS and cause encephalitis within 5-7 days (Thormar et al. 1988).

By reproducing key features of the disease, inoculation of ferrets with human isolates provides unique insights in SSPE pathogenesis. The findings emphasize the importance of the host's immune response, especially the humoral response, in the establishment of a persistent morbillivirus infection in the CNS. Even though the intracerebral route of inoculation constitutes a major drawback of this model, it merits further development as more ferret-specific reagents for the assessment of the immune response become available.

\section{Morbillivirus Neuroinvasion}

Due to the high incidence of CNS involvement associated with CDV infections, morbillivirus neuroinvasion has been extensively studied in dogs and more recently in ferrets (Axthelm and Krakowka 1987; Bonami et al. 2007; Rudd et al. 2006; Vandevelde and Zurbriggen 2005). In dogs experimentally infected with a neurovirulent strain, the outcome is determined by the individual's ability to mount a rapid and specific immune response. Compared to complete recovery without CNS involvement, persistent CNS infection was associated with a delayed and reduced immune response, while animals that died during the acute disease phase were unable to mount any response (Appel et al. 1982). The regular presence of extravascular infected lymphocytes in the white matter and the choroid plexus of CDVinfected dogs during the acute disease phase was indicative of neurovasion via the hematogenous route (Summers et al. 1979), which may be facilitated by alterations of the blood-brain barrier resulting from direct infection of endothelial cells (Axthelm and Krakowka 1987).

Using an eGFP-expressing derivative of A75/17 that retained parental virulence and tropism in the ferret model, it was shown that neuroinvasion occurred not only hematogenously through infected circulating lymphocytes, but also anterogradely via the olfactory signaling route (Rudd et al. 2006). In fact, the earliest macroscopically detectable infected foci in the brain were located in the olfactory bulb, emphasizing the importance of this route of entry for CNS dissemination. CNS invasion only occurred after extensive infection of immune and epithelial tissues, when the animal was already highly immunosuppressed, indicating that morbillivirus neuroinvasion is a late event and requires an inefficient or absent immune response. In a follow-up study, it was shown that the duration of the infection in the absence of an immune response, and not differences in attachment protein-mediated tropism, determines the ability of a CDV strain to invade the CNS (Bonami et al. 2007). 


\section{Conclusion and Perspectives}

The recognition that CDV causes several pathologies in its natural hosts that are similar to MV-associated disease syndromes in humans has promoted the study of host-CDV interactions as a model for measles. Compared to non-human primates or even dogs, ferrets are relatively inexpensive small animals that do not require costly facilities and are easy to house and manipulate. CDV in ferrets recapitulates the clinical signs of measles in humans including the typical rash, fever, severe leukopenia, and general immunosuppression as well as gastrointestinal and respiratory involvement. The study of CDV infection in ferrets is therefore increasingly used as a model for pathogenesis studies and vaccine development. The ongoing effort to develop ferret-specific immunological tools and the advances in the genetic manipulation of morbilliviruses will further increase the attractivity of this model for morbillivirus research.

\section{References}

Alldinger S, Wunschmann A, Baumgartner W, Voss C, Kremmer E (1996) Up-regulation of major histocompatibility complex class II antigen expression in the central nervous system of dogs with spontaneous canine distemper virus encephalitis. Acta Neuropathol 92:273-280

Appel MJ, Harris WV (1988) Antibody titers in domestic ferret jills and their kits to canine distemper virus vaccine. J Am Vet Med Assoc 193:332-333

Appel MJ, Shek WR, Summers BA (1982) Lymphocyte-mediated immune cytotoxicity in dogs infected with virulent canine distemper virus. Infect Immun 37:592-600

Appel MJ, Shek WR, Shesberadaran H, Norrby E (1984) Measles virus and inactivated canine distemper virus induce incomplete immunity to canine distemper. Arch Virol 82:73-82

Appel MJ, Summers BA (1995) Pathogenicity of morbilliviruses for terrestrial carnivores. Vet Microbiol 44:187-191

Atabani SF, Byrnes AA, Jaye A, Kidd IM, Magnusen AF, Whittle H, Karp CL (2001) Natural measles causes prolonged suppression of interleukin-12 production. J Infect Dis 184:1-9

Axthelm MK, Krakowka S (1987) Canine distemper virus: the early blood-brain barrier lesion. Acta Neuropathol 75:27-33

Bonami F, Rudd PA, von Messling V (2007) Disease duration determines canine distemper virus neurovirulence. J Virol 81:12066-12070

Brown HR, Thormar H, Barshatzky M, Wisniewski HM (1985) Localization of measles virus antigens in subacute sclerosing panencephalitis in ferrets. Lab Anim Sci 35:233-237

Bush M, Montali RJ, Brownstein D, James AE Jr, Appel MJ (1976) Vaccine-induced canine distemper in a lesser panda. J Am Vet Med Assoc 169:959-960

Cabasso VJ, Stebbins MR, Cox HR (1953) Active immunization of ferrets by simultaneous injections of avianized canine distemper vaccine and anticanine distemper hyperimmune serum. Cornell Vet 43:179-183

Carpenter JW, Appel MJ, Erickson RC, Novilla MN (1976) Fatal vaccine-induced canine distemper virus infection in black-footed ferrets. J Am Vet Med Assoc 169:961-964

Chalmers WS, Baxendale W (1994) A comparison of canine distemper vaccine and measles vaccine for the prevention of canine distemper in young puppies. Vet Rec 135:349-353

Cherpillod P, Tipold A, Griot-Wenk M, Cardozo C, Schmid I, Fatzer R, Schobesberger M, Zurbriggen R, Bruckner L, Roch F et al (2000) DNA vaccine encoding nucleocapsid and surface proteins of wild type canine distemper virus protects its natural host against distemper. Vaccine 18:2927-2936 
Confer AW, Kahn DE, Koestner A, Krakowka S (1975) Biological properties of a canine distemper virus isolate associated with demyelinating encephalomyelitis. Infect Immun 11:835-844

Dahl L, Jensen TH, Gottschalck E, Karlskov-Mortensen P, Jensen TD, Nielsen L, Andersen MK, Buckland R, Wild TF, Blixenkrone-Moller M (2004) Immunization with plasmid DNA encoding the hemagglutinin and the nucleoprotein confers robust protection against a lethal canine distemper virus challenge. Vaccine 22:3642-3648

Danesh A, Seneviratne C, Cameron CM, Banner D, Devries ME, Kelvin AA, Xu L, Ran L, Bosinger SE, Rowe T et al (2008) Cloning, expression and characterization of ferret CXCL10. Mol Immunol 45:1288-1297

Devaux P, von Messling V, Songsungthong W, Springfeld C, Cattaneo R (2007) Tyrosine 110 in the measles virus phosphoprotein is required to block STAT1 phosphorylation. Virology 360: $72-83$

Dorries R, Ter Meulen V (1984) Detection and identification of virus-specific, oligoclonal IgG in unconcentrated cerebrospinal fluid by immunoblot technique. J Neuroimmunol 7:77-89

Ek-Kommonen C, Rudback E, Anttila M, Aho M, Huovilainen A (2003) Canine distemper of vaccine origin in European mink, Mustela lutreola - a case report. Vet Microbiol 92:289-293

Fischer L, Tronel JP, Pardo-David C, Tanner P, Colombet G, Minke J, Audonnet JC (2002) Vaccination of puppies born to immune dams with a canine adenovirus-based vaccine protects against a canine distemper virus challenge. Vaccine 20:3485-3497

Fischer L, Tronel JP, Minke J, Barzu S, Baudu P, Audonnet JC (2003) Vaccination of puppies with a lipid-formulated plasmid vaccine protects against a severe canine distemper virus challenge. Vaccine 21:1099-1102

Fontana JM, Bankamp B, Bellini WJ, Rota PA (2008) Regulation of interferon signaling by the C and $V$ proteins from attenuated and wild-type strains of measles virus. Virology 374:71-81

Fox JG (1998) Biology and diseases of the ferret. Wiley-Blackwell, New York

Gans HA, Arvin AM, Galinus J, Logan L, DeHovitz R, Maldonado Y (1998) Deficiency of the humoral immune response to measles vaccine in infants immunized at age 6 months. JAMA 280:527-532

Gill JM, Hartley WJ, Hodgkinson NL (1988) An outbreak of post-vaccinal suspected distemperlike encephalitis in farmed ferrets (Mustela putorius furo) NZ Vet J 36:173-176

Gillespie JH, Rickard CG (1956) Encephalitis in dogs produced by distemper virus. Am J Vet Res 17:103-108

Gorham JR, Leader RW, Gutierrez JC (1954) Distemper immunization of ferrets by nebulization with egg adapted virus. Science 119:125-126

Greenacre CB (2003) Incidence of adverse events in ferrets vaccinated with distemper or rabies vaccine: 143 cases (1995-2001) J Am Vet Med Assoc 223:663-665 virology, 5th edn. Philadelphia, Lippincott Williams Wilkins, pp 1550-1585

Griot C, Moser C, Cherpillod P, Bruckner L, Wittek R, Zurbriggen A, Zurbriggen R (2004) Early DNA vaccination of puppies against canine distemper in the presence of maternally derived immunity. Vaccine 22:650-654

Hoover JP, Baldwin CA, Rupprecht CE (1989) Serologic response of domestic ferrets (Mustela putorius furo) to canine distemper and rabies virus vaccines. J Am Vet Med Assoc 194:234-238

Hsu KH, Lubeck MD, Bhat BM, Bhat RA, Kostek B, Selling BH, Mizutani S, Davis AR, Hung PP (1994) Efficacy of adenovirus-vectored respiratory syncytial virus vaccines in a new ferret model. Vaccine 12:607-612

Katz M, Rorke LB, Masland WS, Koprowski H, Tucker SH (1968) Transmission of an encephalitogenic agent from brains of patients with subacute sclerosing panencephalitis to ferrets. Preliminary report. N Engl J Med 279:793-798

Kauffman CA, Bergman AG, O'Connor RP (1982) Distemper virus infection in ferrets: an animal model of measles-induced immunosuppression. Clin Exp Immunol 47:617-625

Krakowka S (1982) Mechanisms of in vitro immunosuppression in canine distemper virus infection. J Clin Lab Immunol 8:187-196

Krakowka S, Cockerell G, Koestner A (1975) Effects of canine distemper virus infection on lymphoid function in vitro and in vivo. Infect Immun 11:1069-1078 
Krakowka S, Axthelm MK, Johnsen GC (1985) Canine distemper virus. In: Olsen RG, Krakowka S, Blakeslee JR (eds) Comparative pathobiology of viral diseases. Boca Raton, FL, CRC, pp 137-164

Krakowka S, Ringler SS, Lewis M, Olsen RG, Axthelm MK (1987) Immunosuppression by canine distemper virus: modulation of in vitro immunoglobulin synthesis, interleukin release and prostaglandin E2 production. Vet Immunol Immunopathol 15:181-201

Loeffler IK, Howard J, Montali RJ, Hayek LA, Dubovi E, Zhang Z, Yan Q, Guo W, Wildt DE (2007) Serosurvey of ex situ giant pandas (Ailuropoda melanoleuca) and red pandas (Ailurus fulgens) in China with implications for species conservation. J Zoo Wildl Med 38:559-566

Maher JA, DeStefano J (2004) The ferret: an animal model to study influenza virus. Lab Anim (NY) 33:50-53

McCullough B, Krakowka S, Koestner A (1974) Experimental canine distemper virus-induced lymphoid depletion. Am J Pathol 74:155-170

McKenna MC, Bell SK (1997) Classification of mammals above the species level. Columbia University Press, New York

McQuaid S, Cosby SL, Koffi K, Honde M, Kirk J, Lucas SB (1998) Distribution of measles virus in the central nervous system of HIV-seropositive children. Acta Neuropathol 96:637-642

Mehta PD, Thormar H (1979) Immunological studies of subacute measles encephalitis in ferrets: similarities to human subacute sclerosing panencephalitis. J Clin Microbiol 9:601-604

Moody KD, Bowman TA, Lang CM (1985) Laboratory management of the ferret for biomedical research. Lab Anim Sci 35:272-279

Morris JA, Coburn DR, O'Connor JR (1954) Rapid protection of ferrets against fully virulent distemper virus with nebulized attenuated distemper virus. Cornell Vet 44:198-207

Moss WJ, Ryon JJ, Monze M, Griffin DE (2002) Differential regulation of interleukin (IL)-4, IL5, and IL-10 during measles in Zambian children. J Infect Dis 186:879-887

Nagano I, Nakamura S, Yoshioka M, Kogure K (1991) Immunocytochemical analysis of the cellular infiltrate in brain lesions in subacute sclerosing panencephalitis. Neurology 41:1639-1642

Ochi A, Danesh A, Seneviratne C, Banner D, Devries ME, Rowe T, Xu L, Ran L, Czub M, Bosinger SE et al (2008) Cloning, expression and immunoassay detection of ferret IFNgamma. Dev Comp Immunol 32:890-897

Ohno S, Ono N, Takeda M, Takeuchi K, Yanagi Y (2004) Dissection of measles virus V protein in relation to its ability to block alpha/beta interferon signal transduction. J Gen Virol 85:2991-2999

Osterhaus AD, Fouchier RA, Kuiken T (2004) The aetiology of SARS: Koch's postulates fulfilled. Philos Trans R Soc Lond B Biol Sci 359:1081-1082

Palosaari H, Parisien JP, Rodriguez JJ, Ulane CM, Horvath CM (2003) STAT protein interference and suppression of cytokine signal transduction by measles virus $V$ protein. J Virol 77:7635-7644

Pardo MC, Bauman JE, Mackowiak M (1997) Protection of dogs against canine distemper by vaccination with a canarypox virus recombinant expressing canine distemper virus fusion and hemagglutinin glycoproteins. Am J Vet Res 58:833-836

Pardo MC, Tanner P, Bauman J, Silver K, Fischer L (2007) Immunization of puppies in the presence of maternally derived antibodies against canine distemper virus. J Comp Pathol 137 Suppl 1:S72-S75

Pearson GL (1977) Vaccine-induced canine distemper virus in black-footed ferrets. J Am Vet Med Assoc 170:103, 106, 109

Pollock RV, Carmichael LE (1982) Maternally derived immunity to canine parvovirus infection: transfer, decline, and interference with vaccination. J Am Vet Med Assoc 180:37-42

Qin Q, Wei F, Li M, Dubovi EJ, Loeffler IK (2007) Serosurvey of infectious disease agents of carnivores in captive red pandas (Ailurus fulgens) in China. J Zoo Wildl Med 38:42-50

Quesenberry KE (1996) Basic approach to veterinary care. In: Hillyer EV, Quesenberry KE (eds) Ferrets, rabbits, and rodents: clinical medicine and surgery. W.B. Saunders, Philadelphia, pp 14-25

Rockborn G, Norrby E, Lannek N (1965) Comparison between the immunizing effect in dogs and ferrets of living distemper vaccines, attenuated in dog tissue cultures and embryonated eggs. Res Vet Sci 6:423-427 
Rudd PA, Cattaneo R, von Messling V (2006) Canine distemper virus uses both the anterograde and the hematogenous pathway for neuroinvasion. J Virol 80:9361-9370

Schluederberg A, Lamm SH, Landrigan PJ, Black FL (1973) Measles immunity in children vaccinated before one year of age. Am J Epidemiol 97:402-409

Schneider-Schaulies J, Niewiesk S, Schneider-Schaulies S, ter Meulen V (1999) Measles virus in the CNS: the role of viral and host factors for the establishment and maintenance of a persistent infection. J Neurovirol 5:613-622

Schobesberger M, Summerfield A, Doherr MG, Zurbriggen A, Griot C (2005) Canine distemper virus-induced depletion of uninfected lymphocytes is associated with apoptosis. Vet Immunol Immunopathol 104:33-44

Senchak AJ, Sato AK, Vazquez R, Keller CE, Cable BB (2007) Characterization of transforming growth factors beta1 and 2 in ferrets (Mustela putorius furo) Comp Med 57:594-596

Shen DT, Gorham JR, Evermann JF, McKeirnan AJ (1984) Comparison of subcutaneous and intramuscular administration of a live attenuated distemper virus vaccine in ferrets. Vet Rec $114: 42-43$

Sips GJ, Chesik D, Glazenburg L, Wilschut J, De Keyser J, Wilczak N (2007) Involvement of morbilliviruses in the pathogenesis of demyelinating disease. Rev Med Virol 17:223-244

Stephensen CB, Welter J, Thaker SR, Taylor J, Tartaglia J, Paoletti E (1997) Canine distemper virus (CDV) infection of ferrets as a model for testing Morbillivirus vaccine strategies: NYVAC- and ALVAC-based CDV recombinants protect against symptomatic infection. J Virol $71: 1506-1513$

Strating A (1975) Measles vaccine in dogs: efficacy against aerosol challenge with virulent canine distemper virus. J Am Vet Med Assoc 167:59-62

Summers BA, Greisen HA, Appel MJ (1979) Early events in canine distemper demyelinating encephalomyelitis. Acta Neuropathol 46:1-10

Summers BA, Greisen HA, Appel MJ (1984) Canine distemper encephalomyelitis: variation with virus strain. J Comp Pathol 94:65-75

Svitek N, von Messling V (2007) Early cytokine mRNA expression profiles predict Morbillivirus disease outcome in ferrets. Virology 362:404-410

Tetteh JK, Addae MM, Ishiwada N, Yempewu SM, Yamaguchi S, Ofori-Adjei D, Kamiya H, Komada Y, Akanmori BD (2003) Plasma levels of Th1 and Th2 cytokines in Ghanaian children with vaccine-modified measles. Eur Cytokine Netw 14:109-113

Thormar H, Mehta PD, Lin FH, Brown HR, Wisniewski HM (1983) Presence of oligoclonal immunoglobulin $\mathrm{G}$ bands and lack of matrix protein antibodies in cerebrospinal fluids and sera of ferrets with measles virus encephalitis. Infect Immun 41:1205-1211

Thormar H, Mehta PD, Barshatzky MR, Brown HR (1985) Measles virus encephalitis in ferrets as a model for subacute sclerosing panencephalitis. Lab Anim Sci 35:229-232

Thormar H, Brown HR, Goller NL, Barshatzky MR, Wisniewski HM (1988) Transmission of measles virus encephalitis to ferrets by intracardiac inoculation of a cell-associated SSPE virus strain. APMIS 96:1125-1128

van Moll P, Alldinger S, Baumgartner W, Adami M (1995) Distemper in wild carnivores: an epidemiological, histological and immunocytochemical study. Vet Microbiol 44:193-199

Vandevelde M, Zurbriggen A (2005) Demyelination in canine distemper virus infection: a review. Acta Neuropathol 109:56-68

Vandevelde M, Kristensen F, Kristensen B, Steck AJ, Kihm U (1982) Immunological and pathological findings in demyelinating encephalitis associated with canine distemper virus infection. Acta Neuropathol 56:1-8

Vandevelde M, Zurbriggen A, Steck A, Bichsel P (1986) Studies on the intrathecal humoral immune response in canine distemper encephalitis. J Neuroimmunol 11:41-51

von Messling V, Springfeld C, Devaux P, Cattaneo R (2003) A ferret model of canine distemper virus virulence and immunosuppression. J Virol 77:12579-12591

von Messling V, Milosevic D, Cattaneo R (2004) Tropism illuminated: lymphocyte-based pathways blazed by lethal morbillivirus through the host immune system. Proc Natl Acad Sci U S A 101:14216-14221 
von Messling V, Svitek N, Cattaneo R (2006) Receptor (SLAM [CD150]) recognition and the V protein sustain swift lymphocyte-based invasion of mucosal tissue and lymphatic organs by a morbillivirus. J Virol 80:6084-6092

Welter J, Taylor J, Tartaglia J, Paoletti E, Stephensen CB (1999) Mucosal vaccination with recombinant poxvirus vaccines protects ferrets against symptomatic CDV infection. Vaccine 17:308-318

Welter J, Taylor J, Tartaglia J, Paoletti E, Stephensen CB (2000) Vaccination against canine distemper virus infection in infant ferrets with and without maternal antibody protection, using recombinant attenuated poxvirus vaccines. J Virol 74:6358-6367

Wilkins J, Wehrle PF (1979) Additional evidence against measles vaccine administration to infants less than 12 months of age: altered immune response following active/passive immunization. J Pediatr 94:865-869

Williams ES, Anderson SL, Cavender J, Lynn C, List K, Hearn C, Appel MJ (1996) Vaccination of black-footed ferret (Mustela nigripes) x Siberian polecat (M. eversmanni) hybrids and domestic ferrets (M. putorius furo) against canine distemper. J Wildl Dis 32:417-423

Wimsatt J, Jay MT, Innes KE, Jessen M, Collins JK (2001) Serologic evaluation, efficacy, and safety of a commercial modified-live canine distemper vaccine in domestic ferrets. Am J Vet Res 62:736-740

Wimsatt J, Biggins D, Innes K, Taylor B, Garell D (2003) Evaluation of oral and subcutaneous delivery of an experimental canarypox recombinant canine distemper vaccine in the Siberian polecat (Mustela eversmanni) J Zoo Wildl Med 34:25-35

Zilliox MJ, Moss WJ, Griffin DE (2007) Gene expression changes in peripheral blood mononuclear cells during measles virus infection. Clin Vaccine Immunol 14:918-923 